\title{
A PRODUÇÃO DO CONHECIMENTO SOBRE A CONFIGURAÇÃO DO CAMPO DA EDUCAÇÃO PROFISSIONAL E TECNOLÓGICA ${ }^{1}$
}

\author{
M. CIAVATTA \\ Universidade Federal Fluminense (UFF) \\ mciavatta@terra.com.br
}

Artigo submetido em agosto/2016 e aceito em agosto/2016

DOI: $10.15628 /$ holos.2016.5013

\section{RESUMO}

Esse texto objetiva refletir sobre a produção do conhecimento sobre a configuração do campo da educação profissional e tecnológica. Para tanto, discorremos sobre a sociedade onde se produzem os conhecimentos e sobre alguns cânones das ciências humanas e sociais aplicadas à educação e sobre alguns exemplos de políticas educacionais de educação profissional e tecnológica que se apresentariam como configuração. E, por último, procedemos à sua apreciação crítica.

PALAVRAS-CHAVE: Produção do conhecimento, Educação profissional, Campo científico.

\section{THE KNOWLEDGE PRODUCTION ON THE CONFIGURATION OF THE VOCATIONAL TECHNICAL AND TECHNOLOGICAL EDUCATION FIELD}

\section{ABSTRACT}

This text aims at ponding on the knowledge production on the configuration of the vocational technical and technological education field. Therefore, we expatiate on the society that produces the knowledge, as well as some human and social science canons applied to education.

Also, there are some examples of educational policies for vocational technical and technological education that are presented on the configuration. Last, we proceed to a critical assessment.

KEYWORDS: Knowledge production, Vocational Technical Education, Scientific Field.

\footnotetext{
1 Texto preparado para o III Colóquio Nacional "A produção do conhecimento em Educação Profissional. Plano Nacional de Educação (2014-2024)", Natal, IFRN, 04 a 07 de agosto de 2015.
} 
"Configuração: a forma exterior de um corpo; conformação, aspecto, figura, feitio" (NOVO, 2004.).

\section{INTRODUÇÃO}

Para pensar a produção do conhecimento sobre a configuração do campo da Educação Profissional e Tecnológica (EPT), em primeiro lugar, precisamos apreciar o uso do termo e refletir sobre a sociedade onde se produzem os conhecimentos e sobre alguns cânones das ciências humanas e sociais aplicadas à educação. A seguir, buscar compreender alguns exemplos de políticas educacionais de educação profissional e tecnológica que se apresentariam como configuração. Por último, proceder à sua apreciação crítica.

Do ponto de vista teórico-metodológico, tomando por base as ciências humanas e sociais, rejeitamos, como ponto de partida, os vieses funcionalistas e positivistas. No primeiro caso, ordena-se a realidade segundo fins pragmáticos e objetivos mercadológicos; pela segunda orientação, a positivista, descreve-se e quantifica-se o real nas suas inúmeras manifestações, segundo critérios de eficiência, eficácia, produtividade próprios dos diversos ramos da indústria, da agroindústria e dos serviços.

O termo configuração é de uso corrente hoje, no mundo acadêmico. Uma vertente de interpretação, remete à ideia de rede, de estrutura de relações, tal com se apresenta no trabalho de Norbert Elias (1994) sobre "a sociedade dos indivíduos". Há relações de interdependência no interior das estruturas de pensamento e de ação, que ser formam nas redes de relações entre os indivíduos e as sociedades (ELIAS, 1994). Para Heinich (2001), Elias substitui "a causalidade linear, que liga substâncias separadas, pela circularidade da interdependência das funções" (p. 118).

Para Elias, a inteligibilidade do movimento das relações sociais é lacunar, necessita da palavra. Mas a própria nomeação dos seres é uma forma de apropriação precária. Assim, a palavra configuração é utilizada para buscar dar conta do entendimento aproximado do padrão de comportamentos, ações e relações em um grupo de indivíduos. O exemplo do jogo é recorrente em sua obra: "cada elemento da conversação não veio de um ou de outro interlocutor tomado isoladamente, mas nasceu precisamente da relação entre os dois" (apud HEINICH, op. cit., p. 121).

Situada em um outro campo teórico, nossa reflexão tem por base o trabalho como fonte de pesquisa, dentro de uma visão dialética da realidade, com base no materialismo histórico (MARX, 1977 e outros). Em primeiro lugar, distinguimos o trabalho como atividade ontocriativa do ser humano, sobre a natureza, para daí retirar os meios de vida e de reprodução da espécie. Mas o trabalho existe também nas suas formas históricas de servidão, escravidão, assalariamento e submissão pela venda de sua força de trabalho e alienação do produto do trabalho, do conhecimento produzido e da sociabilidade gerada no trabalho coletivo, como expõe Marx (1980), no fetiche da mercadoria.

Para compreender a produção do conhecimento sobre a configuração da EPT, além de desvelar a contradição capital e trabalho, é preciso se ocupar das diversas manifestações da vida humana: o sentido do trabalho, as diversas formas de sociabilidade, os múltiplos aspectos que concorrem para manifestar a historicidade da vida. Se queremos reconstruir a história vivida pelos sujeitos sociais, ao nível do pensamento, devemos fazer apelo à teoria, às categorias que nos 
ajudam a ordenar o caos dos acontecimentos e apreciá-los sob uma nova luz, além do aparente, como conceitos, como "síntese de múltiplas determinações" (MARX, 1977, p. 229), sem perder o elo de sua historicidade em espaços-tempos determinados.

Neste texto, primeiro nos detemos sobre o uso do termo configuração da EPT, no contexto do mundo acadêmico e digital; a seguir, procedemos à análise da implementação de algumas políticas educacionais através dos Decretos n. 2.208/1997 e 5.154/2004, do Pronatec, Lei n. 12.513/2011 e do recente documento "Pátria Educadora" (BRASIL, 2015). A seguir, tratamos da produção do conhecimento dentro da visão histórico-dialética da totalidade social.

\section{A CONFIGURAÇÃO DOS SISTEMAS ORGANIZACIONAIS E A PESQUISA}

Tratando da história do presente, Antoine Prost (2000), diz que cada vez que o historiador aborda um novo tema, ele deve repensá-lo colocando-se no lugar vivenciado, sentido, pensado por aqueles que ele vai estudar. Significa reconstituir seus passos em sua forma de vida, de moradia, de vestir-se, de alimentar-se, de trabalhar, pelo uso dos objetos que the serviam, pelas mudanças que lhes trouxeram. Deve reconstituir seu universo mental, sua percepção do mundo, seus desejos, suas aspirações, sua religião. Deve entregar-se a uma espécie de experiência pelos traços interpostos em sua atividade de historiador (p. 3). ${ }^{2}$

Prost fala também no exercício de imaginação que o historiador deve fazer nesse inusitado percurso de produção do conhecimento. O tratamento do tema "configuração de educação profissional e tecnológica" obriga-nos a pensar em uma nova realidade de estudos e de práticas na sociedade em que vivemos e no sentido de como somos educados.

No Brasil, assumimos os anos 1990 como um marco de transformações sociais que permitem situar o sentido do termo configuração e das novas práticas educacionais que lhe dão conteúdo. Particularmente, desde os anos 1940, na chamada Nova República do Presidente Vargas, os segmentos empresariais sempre estiveram à frente da formação profissional dos trabalhadores. Mas foi na década de 1990, com a implantação das políticas neoliberais, que a ideologia da prevalência das necessidades do mercado, sobre outros valores da vida social, disseminou-se amplamente, no campo econômico, político e cultural.

A educação, como um todo, em todos os seus níveis escolares, por sua função instrumental do Estado e pelas aspirações de mobilidade social, não podia estar imune ao intenso processo de ideologização que ocorreu. A formação profissional que, até então, era um ramo do sistema nacional de ensino, recebeu a denominação de educação profissional (LDB 9.394/1996, Art. 39). A função da educação como formação humana, síntese de todos os aspectos do desenvolvimento humano, foi subsumida à formação para o trabalho de acordo com as necessidades empresariais, legitimada pela doutrina neoliberal. ${ }^{3}$

O neoliberalismo retomou princípios e valores do liberalismo clássico (individualismo, liberdade política e econômica, defesa da propriedade privada) adaptados aos avanços da ciência e das tecnologias para o mercado. Suas determinações expressam-se nas necessidades declaradas

\footnotetext{
2 Tradução livre da autora.

${ }^{3}$ As ideias neoliberais foram geradas nos países ricos, onde foram objeto de estudo e implementação desde o final dos anos 1970, com base nos estudos do grupo que se reuniu em Mont Pélérin, Suiça, em 1947, por convocação do economista Friedrich Hayek, para preservar os princípios e valores do liberalismo.
} 
de reestruturação produtiva, de flexibilização da produção e das relações laborais, corte de custos e de postos de trabalho, Estado mínimo, privatização do público, fórmulas internacionalizadas através da globalização das ideias e dos produtos (entre outros, ver GENTILI; SILVA, 1994; SADER; GENTILI, 1995) e da permanência do capitalismo dependente que se fortaleceu com o suporte ideológico dessas ideias (FERNANDES, 1975; MARINI, 2000).

No plano supra-estrutural e ideológico produziu-se uma espécie de "nova língua", uma nouveau langue de acordo com Bourdieu e Wacquant (2000), com a função de afirmar um tempo de pensamento único, de solução única para a crise gerada, consequentemente, irreversível. Neste contexto, destacaram-se as noções de globalização, Estado mínimo, reengenharia, reestruturação produtiva, sociedade pós-industrial, sociedade pós-classista, sociedade do conhecimento, qualidade total, empregabilidade etc., cuja função era e é, ainda, justificar a necessidade de reformas profundas no aparelho do Estado e novas relações capital/trabalho, sempre a serviço da acumulação flexível do capital (HARVEY, 1992).

Duas décadas depois, o termo configuração aplica-se à Educação Profissional e Tecnológica (EPT) anunciando o que seria a nova realidade criada para designar a formação profissional adequada aos novos tempos da pós-modernidade. Na língua-mãe da informática, configuração é set, form, shape, cutout e prende-se à expansão da cultura digital para todos os segmentos sociais, através de seus inúmeros hardwares (computadores e note books Asus, Sony, HP, LG etc. e telefones celulares, Ipads, smartphones, impressoras, scanners, monitores, mouses, teclados) e softwares (programas) tais como, Windows, Word, MacOS, Linux, Power Point, Excel, e-mail e aplicativos-apps: Outlook, Facebook, Instagram, Whatsapps, Waze, Google maps etc.).

Na língua portuguesa, configurar é dar forma ou figura de, conformar, ou ser sinal de, denotar, caracterizar. Configuração é a forma exterior de um corpo, conformação, aspecto, figura, feitio. Mas o termo parece estar mais próximo de seu uso em sistemas informatizados onde significa um "conjunto de parâmetros, de componentes, periféricos e programas que determinam as possibilidades e a forma de funcionamento de um computador, de seu sistema operacional e de seus aplicativos". Há também vários usos no campo da eletrônica (NOVO, 2004). Um exemplo trivial do uso do termo encontramos na comunicação de uma empresa proteção de computadores, a Avast: "configurar o Firewall para a rede a que você está conectado agora", o que significou por em operação o nível de segurança para o computador.

Tratando da transformação do fordismo à acumulação flexível, no seu clássico estudo sobre a "condição pós-moderna", Harvey (op. cit.), indica alguns aspectos da acumulação flexível que deram nova configuração ao mundo econômico com repercussão em outros aspectos da vida social, em confronto com a rigidez da produção fordista: "flexibilidade nos processos de trabalho, dos mercados de trabalho, dos processos e dos produtos" (140, grifos do autor). Criam-se novos setores na produção, nas finanças (a informatização, superando as noções de espaço e tempo, no comércio (intensificado pelo mercado global), na organização do trabalho (cujo exemplo pioneiro é o toyotismo), expandem-se novas tecnologias.

O autor assinala dois grandes desenvolvimentos paralelos: as informações precisas e atualizadas tornam-se valores de mercado altamente prezados, assim como o acesso e controle da informação de uso dos setores corporativos para a obtenção de lucros nos mercados monetários e financeiros. Outras informações também são privilegiadas, como os conhecimentos científicos e técnicos, as políticas de governo e mudanças políticas na sociedade. 
Nos sistemas de produção flexíveis, os novos produtos e suas técnicas mais avançadas, as descobertas científicas, todos concorrem para as vantagens competitivas. Nos países com ambientes de alta tecnologia, é grande a concorrência por patentear novas descobertas científicas e pessoal especializado. É comum os melhores estudantes dos países em desenvolvimento permanecerem nos países onde vão fazer seus estudos de pós-graduação, onde podem ter os laboratórios, equipes de pesquisa e compensações financeiras inexistentes em seus países de origem.

Harvey (ibid.), falando nos anos 1990, há vinte anos atrás, salienta a notável expansão da "produção organizada do conhecimento" como uma atividade mercantilizada entre os sistemas universitários do mundo capitalista avançado, "guardiões do conhecimento e da sabedoria para produtores subordinados do conhecimento a soldo do capital corporativo". Cita, como exemplo, as conexões da Stanford University com a indústria de 'alta tecnologia' do Vale do Silício ${ }^{4}$ ou a Rota MIT (Massachusets Institute of Technology) - Boston, que são "configurações bastante novas e especiais da era da acumulação flexível" (p. 151, grifo nosso).

O segundo grande desenvolvimento indicado pelo autor foram as reformas para a expansão do sistema capitalista. Estas teriam começado com a desregulamentação do sistema financeiro, já nos anos 1930, ganhado impulso após a "crise do petróleo em 1973", explicitando-se e expandindo-se para todos os centros financeiros do mundo em torno de 1986.

"As fronteiras entre funções distintivas como bancos. corretoras, serviços financeiros, financiamento habitacional, crédito ao consumidor etc. tornaram-se cada vez mais porosas, ao mesmo tempo que novos mercados futuros de mercadorias de ações, de moedas ou de dívidas surgiram em toda parte, introduzindo o tempo futuro no tempo presente de maneiras estarrecedoras" ( $p$. 153-54).

Tomando a Educação Profissional e Tecnológica (EPT) como um sistema adaptado às necessidades da produção industrial e virtual e à área de serviços contemporâneos, falar em sua configuração significa introduzir ou modificar dados ou parâmetros, de modo que ele possa absorver determinado tipo de atividade. Assim, é possível falar em configurar uma proposta ou um sistema de treinamento dentro de uma empresa para atender a novas demandas, ou habilitar determinadas áreas para que funcionem dentro de certos parâmetros e apresentem outros resultados. $^{5}$

\footnotetext{
4 “O Vale do Silício (em inglês: Silicon Valley), na Califórnia, Estados Unidos, é uma região na qual está situado um conjunto de empresas implantadas a partir da década de 1950 com o objetivo de gerar inovações científicas e tecnológicas, destacando-se na produção de circuitos eletrônicos, na eletrônica e informática" (...) o impulso para o desenvolvimento se deu com a Segunda Guerra Mundial e principalmente durante a Guerra Fria, devido à corrida armamentista e aeroespacial. Foram as indústrias eletrônicas do Vale do Silício que forneceram transistores para mísseis e circuitos integrados para os computadores que guiaram as naves Apollo.

Muitas empresas que hoje estão entre as maiores do mundo nasceram e estão presentes nesta região: Apple Inc., Altera, Google, Facebook, NVIDIA Corporation, Electronic Arts, Symantec, Advanced Micro Devices (AMD), eBay, Maxtor, Yahoo!, Hewlett-Packard (HP), Intel, Foursys, Microsoft (hoje está em Redmond, próximo a Seattle), entre muitas outras". Disponível em https://pt.wikipedia.org/wiki/Vale_do_Sil\%C3\%ADcio. Acesso em 28-07-2015

${ }^{5}$ Agradecemos ao Eng. A. C. Pantoja Franco a interlocução sobre o sentido do termo em sistemas organizacionais e computacionais.
} 


\section{A PESQUISA E AS PRÁTICAS EDUCATIVAS EM EPT: ENTRE A CONFIGURAÇÃO E A TOTALIDADE SOCIAL}

Os nomes dados aos objetos não são denominações aleatórias, são, antes, expressões de realidades emergentes na sociedade que instauram novos modos de ser e de pensar. A realidade social e econômica não muda apenas porque lhe dão outro nome, mas outras denominações atuam no plano ideológico de elaboração de justificativas para a defesa de interesses de grupos e classes sociais. As palavras concorrem para a organização do pensamento e instauram práticas concernentes a seus conteúdos reais ou desejáveis por aqueles que têm o poder da palavra, hoje, em níveis incomensuráveis de disseminação, com o recursos midiáticos das redes sociais.

Em termos de produção do conhecimento, na configuração da EPT, vemos uma concepção de formação (i) que sinaliza a adequação aos temos informatizados das redes de relações técnicas e sociais; (ii) que se orienta pelos interesses pragmáticos da mercantilização do trabalho e de todas as atividades que constituem o mundo do trabalho (sociabilidade, lazer, cultura, religião, educação); (iii) que opera pela fragmentação na análise dos fenômenos conforme a cultura digital, reduzindo-os às suas dimensões factuais e quantitativas.

Apresentamos, brevemente, três expressões principais dessa tendência à configuração da educação profissional pelos ditames empresariais. Em consonância com a ideologia neoliberal que se manifestou na economia, na política, na educação e em outros setores da vida nacional, foram sete anos de implementação estrita do Decreto n. 2.208/1997 (1997 a 2004), com a separação orgânica e financiada, entre o ensino médio e a EPT. Sua revogação pelo Decreto n. 5.1.54/2004, propiciou a "articulação" entre o geral e o específico, dando ensejo a três tipos de cursos. ${ }^{6}$ Permitiu a manutenção dos cursos "subsequentes", de interesse dos trabalhadores que precisavam atualizar sua qualificação ou completar a escolaridade de ensino médio. Manteve os cursos "concomitantes", de duvidosa realização por serem organizados com duas matrículas, em duas instituições conveniadas, supondo-se que apesar das particularidades dos currículos de cada escola, o geral e o específico se articulariam. E criou o curso "integrado" com objetivo de recuperar, em uma matrícula, em uma mesma escola de nível médio técnico, os conhecimentos gerais que fundamentam a prática da educação profissional. ${ }^{7}$

A compreensão e a implantação do ensino médio integrado ainda é um processo em curso, com muitos desafios, sucessos e insucessos. Além da cultura empresarial reducionista da educação pautada pelas necessidades do mercado, sistematizada pelo Decreto n. 2.208/2004, uma iniciativa contraditória tomou forma paralelamente. Enquanto uma equipe de pesquisadores, associações científicas e movimentos sociais, convidada pelo MEC, discutia, criteriosamente e preparava uma versão das Diretrizes Curriculares Nacionais de Educação Profissional e Tecnológica (DCN EPT), a ser levada ao Conselho Nacional de Educação (CNE), anunciou-se o Programa Nacional de Ensino Técnico e Emprego (Pronatec) sob a pauta educacional dos empresários.

O Pronatec adquiriu status de lei (Lei n. 12.513/2011), oferecendo vagas em cursos breves de formação profissional inicial e continuada que, somadas às de ensino técnico, deveriam alcançar o total de 7,9 milhões de matrículas de 2011 a 2014. O Brasil tem 22,5 milhões de jovens entre 15

\footnotetext{
${ }^{6}$ O Decreto 5.154/2004 foi revogado e incorporado à LDB (Lei 9.394/1996) pela Lei n. 11.741/2008.

7 Abstemo-nos de detalhar a implementação do Decreto n. 2.208/1997, porque ele foi objeto de estudo e discussão de muitos trabalhos (entre outros, ver FRIGOTTO; CIAVATTA, 2006; NEY, 2006).
} 
e 24 anos, e cerca de um terço, 7,6 milhões, concluíram o ensino médio e não ingressaram em outro sistema de ensino, superior ou de educação básica (TOKARNIA, 2013). O Pronatec constituiuse em um programa de educação de massa, em detrimento da universalização da educação básica de qualidade, organizada com um currículo integrado entre o ensino médio e a educação profissional. $^{8}$

Tornou-se o mais amplo e financeiramente bem apoiado programa de educação profissional. Em 2011, quando o Programa foi lançado, a expectativa era "reduzir um problema crônico para o crescimento dos serviços e da indústria nacional: a falta demão de obra especializada". O orçamento previsto era de 1 bilhão, sendo 700 milhões para bolsas de estudo e 300 milhões para financiamento estudantil, além o orçamento previsto para a expansão das escolas técnicas, passar das 140 escolas existentes até 2002, para 214 até 2010, ainda no governo Lula, e chegar a 554 até 2013. Além disso, a educação profissional teria o aporte de "3,5 bilhões para escolas do Sistema S - Sesi, Senai, Sesc e Senac", através do BNDES (Banco Nacional de Desenvolvimento Econômico e Social) (PRONATEC, 2011).

Servindo a instituições públicas e, principalmente, privadas,o Pronatec opera dando autonomia para a criação e oferta de vagas e programas de educação profissional e tecnológica. No decorrer de sua implantação, a proposta se estendeu para o Proeja e o Ensino Médio Técnico. Mas foi intensa sua divulgação e os benefícios oferecidos aos alunos das camadas de baixa renda, prometendo preparação imediata para o emprego almejado. Os cursos funcionais de educação profissional, em tese, mais vantajosos que o ensino médio de formação geral, acabaram subsumindo a educação geral e o ensino médio, na ênfase sobre as vantagens no discurso governamental, na mídia e, também, no ideário educacional da população.

Pelos recursos de que dispõe e pela funcionalidade de seus cursos de formação para o trabalho, o Pronatec tem sido objeto de adesão de muitas instituições e, também, de crítica por seu perfil funcional à população brasileira carente de educação básica de qualidade. ${ }^{9}$ Diferente dos países desenvolvidos onde a educação básica de qualidade é universalizada até o ensino médio, e a educação profissional é uma opção depois de uma boa educação geral, no Brasil, o ensino médio e a educação profissional são objeto de polêmica e de políticas ideologizadas segundo a lógica do mercado.

A terceira dessa série de iniciativas dos reformadores empresariais, é o documento "Pátria Educadora" (BRASIL, 2015). É mais uma das iniciativas erráticas da educação brasileira, porque não têm como finalidade a elevação de toda população a um patamar educacional de qualidade. As finalidades estão fora dos sujeitos envolvidos, atendem aos interesses imediatos das classes produtoras que detêm os meios de produção.

Sem a pretensão de esgotar a análise do documento, nos limites deste trabalho, abordaremos alguns aspectos da reforma educacional empresarial que o autor/responsável pretendia implantar no país. Dizemos pretendia, porque Roberto Mangabeira Unger, Ministro de

\footnotetext{
8 A PNAD/IBGE de 2009 registrou "uma situação educacional inaceitável: mais de 14 milhões de analfabetos totais e 29,5 milhões de analfabetos funcionais, o que significa um quarto da população sem escolarização mínima" (LEHER, 2013).

9 Entre outros, ver Lima, 2012; Guimarães, 2012. Até 2014, o Pronatec foi alvo de muita divulgação e de recursos financeiros (v. SENAC, 2014; DILMA, 2014). A explicitação da crise econômica no país indica dificuldades para o Programa (entre outros, GOVERNO, 2015; ), com reações contrárias, principalmente, do Sistema S e dos empresários (entre outros, OLIVEIRA, 2015; FERREIRA; MARIZ, 2015).
} 
Assuntos Estratégicos da Presidência da República, está demissionário da pasta que assumiu (SAìDA, 2015). O que não significa, necessariamente, o arquivamento do documento, já que seu título reitera o slogan do atual governo, "Pátria Educadora", e todo documento tem o sentido da educação defendida pelos empresários, com ampla divulgação, através de documentos, entrevistas, artigos, eventos etc. ${ }^{10}$

Com o olhar de um scholar "iluminado", seu responsável, cria, de forma autóctone, as coordenadas para "a qualificação do ensino básico como obra de reconstrução nacional", subtítulo do documento, no qual nos deteremos por ser o mais explícito, mais recente e representativo dos projetos de reformas educacionais empresariais.

"A qualificação do ensino básico" a que se refere o documento "Pátria Educadora", é o núcleo central que se organiza em duas partes principais: a Tarefa e as Iniciativas. Quanto à Parte I: A Tarefa, a primeira é "O contexto maior da empreitada" que é qualificar o ensino público dentro de "nova estratégia de desenvolvimento nacional" que seja "produtivista, capacitador e democratizante" (p. 4). Seguem-se três Pontos de partida:

1. aproveitar os "experimentos [que] seguiram a lógica da eficiência empresarial";

2. "mudar a maneira de ensinar e aprender", referindo-se ao "enciclopedismo raso e informativo";

3. "organizar a diversidade" de uma educação que tem sido "uniforme no conformismo com a mediocridade" (p. 5-6).

A seguir, vêm:

[a] os "Eixos da qualificação do ensino público";

[b] "Construir o federalismo cooperativo no ensino básico", quando são apresentados vários mecanismos (p. 7-9);

[c] "Mudar o paradigma curricular e pedagógico do ensino básico": [i] pelo "aprofundamento seletivo dos conteúdos"; (p.10); [ii] pelo currículo como "sequência de capacitações" (p. 10-13); [iii] pelas "capacitações pré-cognitivas" onde se destacam disciplina e cooperação (p. 13-15);

[d] a realidade de "Diretores e professores" no país, onde, entre outras observações, estão as críticas às licenciaturas das federais que "deixam-se fascinar, ao gosto de cada catedrático, com o torneio de manual entre filosofias da educação" (p. 15-19);

\footnotetext{
10 “O movimento Todos Pela Educação, criado no ano de 2006 como uma organização da sociedade civil, que toma para si a missão de contribuir para a melhoria da educação básica no Brasil. Considerando-se uma instituição apartidária e plural, o movimento reúne um grupo de empresários, dentre outros, Banco Itaú, Banco Bradesco, Canal Futura, Editora Moderna, Fundação Victor Civita, Grupo Gerdau, Grupo Suzano, Instituto Ayrton Senna, Instituto Camargo e Correa, Organizações Globo, que atuando como anunciador e organizador de uma nova cultura educacional resolveriam todos os problemas sociais: baixa escolaridade, baixa qualidade educacional, miséria, corrupção, violência, etc., até o ano de 2022. Sob o mote de tornar o Brasil verdadeiramente independente através da educação de qualidade, o Todos Pela Educação conta com um grande poder de comunicação na mídia como internet, televisão, jornais e revistas, além do mercado editorial. As concretizações dos seus objetivos já estão visíveis nas escolas como a gestão calcada nos valores empresariais, o uso da avaliação externa, a educação voltada para o mercado, a proposta de horário integral na contramão da formação integral, o investimento na formação do professor através da EaD" (PASSOS, 2014, p. 1).
} 
[é] "Tecnologias e técnicas" cujo "uso criterioso" pode acelerar a transformação do ensino;

[f] "O problema maior: a busca da vanguarda pedagógica" que ainda falta para levar adiante o projeto;

[g] a "obra de libertação e de construção nacional" (p. 19-21).

O tom de ufanismo e de auto-confiança aparece em vários momentos, do qual é exemplar a finalização da "Parte I: A Tarefa": "A nação responderá com ardor. E quebrará as barreiras, objetivas e subjetivas, à execução da obra libertadora" (p. 21). Na "Parte II, As "Iniciativas - Um elenco de ações em ordem aproximada de implementação", o documento apresenta cerca de trinta ações a serem executadas.

Nesta breve apresentação, focalizaremos apenas alguns aspectos do "Pátria Educadora", compartilhando as análises de Luiz Carlos de Freitas (2015) e de José Clóvis de Azevedo (2015).

O primeiro ponto a destacar é a forma elitista, individualista e autoritária de elaboração do documento que ignora e desqualifica a universidade brasileira, a pesquisa, a produção científica em educação, que é abundante no Brasil, em relação a todos os problemas educacionais. Manifesta-se à procura de "uma vanguarda pedagógica", "portadores da luz", na contramão do esforço de vários setores acadêmicos, da pesquisa e da extensão nas universidades, de associações, para produzir conhecimento coletivamente, atuando junto a professores, gestores e movimento socais para a melhoria da educação no país.

Para Freitas (op.cit.), Mangabeira Unger, viveu nos Estados Unidos nas ultimas décadas e "fala de costas". Seu documento não tem referências bibliográficas, não toma por base grandes eventos de reflexão e decisões sobre políticas educacionais, como as Conferências Nacionais de Educação (CONAEs), nem o Plano Nacional de Educação (PNE). Utiliza apenas um "botão reset ou del" na política educacional brasileira produzida até hoje (p. 1-2).

É um documento elitista e conservador porque expõe um ideário e proposta de ações de implementação segundo os padrões do mercado. Reúne "ações de responsabilização, meritocracia e privatização" que são a base política dos reformadores empresariais da educação nos últimos cinco anos, como exige o mercado, através de provas, gratificações, estímulos competitivos como exigência para receber recursos públicos (ibid.). O modelo empresarial está bem configurado em seu texto, como mostra a defesa de "experimentos:

Muitos destes experimentos seguiram a lógica da eficiência empresarial, valendose de práticas como a fixação de metas de desempenho, a continuidade da avaliação, o uso de incentivos e de métodos de cobrança, o acompanhamento e, quando necessário, o afastamento de diretores, a despolitização da escolha de diretores e a individualização do ensino, especialmente para alunos em dificuldade (PÁTRIA, 2015, 'p. 5).

Para Azevedo (op. cit.), o autor "não dialoga com nossa história, não respeita nossas experiências, não recorre ao nosso patrimônio". Sua proposta experimentalista é antagônica às concepções assumidas pelo campo democrático. Identifica-se com as fundações empresariais e os institutos privados (p. 2).

Para Freitas (op. cit.), o autor repete o modelo do relatório que deu início à reforma da educação americana sob o governo Reagan, "A Nation on Risk: The Imperativ for educational reform", em 1983, orientado pelos reformadores empresariais americanos. Freitas e Azevedo 
citam Diana Ravich, que foi Secretária Nacional de Educação, do Governo Bush, e fez a crítica do modelo baseado em testes e responsabilização, conforme o Modelo Empresarial de Mercado, com graves consequências para a educação pública. ${ }^{11}$ Aplica uma visão tecnicista em que avaliar é aplicar testes, premiar ou punir conforme os resultados (AZEVEDO, op. cit., p. 4). Aliás o sistema de bônus já está em curso no Brasil, em alguns estados (v. Rio de Janeiro e São Paulo), transformando o professor em executor de ordens e manuais.

A avaliação é um instrumento necessário vinculado aos processos de trabalho. Deve destinar-se a "resolver os problemas concretos, buscar respostas e com a participação ativa dos sujeitos avaliados. $O$ que não exclui o olhar externo e até a realização de provas, mais como uma dimensão do processo de avaliação" (AZEVEDO, ibid.) As formas uniformizadoras, seletivas e classificatórias, sem levar em conta os limites de acesso das classes populares ao ambiente letrado das classes médias e altas da população, terminam expulsando das escolas grande parte de nossas crianças e adolescentes.

A avaliação tecnicista e quantitativa é um dos pontos mais criticados do documento. Mangabeira assume o PISA (Programme for International Student Assessment) da OCDE (Organização para a Cooperação e Desenvolvimento Econômico - que reúne 34 países desenvolvidos no hemisfério norte) para julgar a educação brasileira. Demonstra ter uma visão reducionista da educação, ao não contextualizar a educação nos seus determinantes sociais e culturais . Além disso, Azevedo considera que "o ranking, a partir da resultados de avaliações como o PISA serve para a mídia e seus aliados desenvolverem uma crescente baixa estima entre os educadores e educandos brasileiros" (op. cit., p. 5).

O documento também demonstra desconhecimento da educação brasileira atual quando considera nosso ensino "enciclopedista". Situando no tempo-espaço da história, até meados do século passado, dentro da tradição humanista que deu conteúdos ao currículo, nossa escola foi depositária e encarregada da transmissão dos conhecimentos que dão forma à cultura ocidental europeia. A partir da reforma do ensino segundo a Lei n. 5.692/1971, com base no modelo americano da compreensive school, ampliou-se o número de disciplinas, mas introduziram-se componentes práticos, tecnologias e formação profissional. Sua expressão principal foi a profissionalização obrigatória no Ensino Médio (2o. Grau) e iniciação profissional no segundo segmento do Ensino Fundamental (1‥ Grau). Com a LDB (Lei n. 9.394/1996) e a introdução dos Parâmetros Curriculares Nacionais (PCNs), houve um progressivo "enxugamento" dos conteúdos curriculares e adequação funcional a um amplo sistema de avaliação seletiva. ${ }^{12}$

Estamos, pois, longe de um sistema enciclopedista. Todo o ensino está orientado para uma educação pragmática e utilitarista, segundo o modelo americano. Azevedo (op.cit.) chama a atenção também para o criador da teoria curricular, Franklin John Bobbit (1876-1969) que expôs

\footnotetext{
${ }^{11} \mathrm{RICH}$, Diana. Vida e morte do grande sistema escolar americano: como os testes padronizados e o modelo de mercado ameaçam a educação. Porto Alegre: Sulina, 2013.

12 Constituído pelo SAEB (Sistema Nacional de Avaliação da Educação Básica), o Enem (Exame Nacional do Ensino Médio), o ENC (Exame Nacional de Cursos conhecido como Provão) posteriormente, substituído pelo Enade (Exame Nacional de Desempenho do Ensino Superior), o Enceja (Exame Nacional de Certificação de Jovens e Adultos ), o Sinaes (Sistema Nacional de Avaliação do Ensino Superior ), a Prova Brasil e o Ideb (Índice de Desenvolvimento da Educação Básica), além da

Avaliação da Pós-Graduação da Capes - o mais antigo sistema de avaliação do país no setor educação, que “configuram um macrossistema de avaliação da qualidade da educação brasileira" (CASTRO, 2009, p. 1, grifo nosso).
} 
uma visão tradicional do currículo escolar, mas a partir do modelo industrial. Combinado à teoria da administração científica do trabalho de F. W. Taylor, engenheiro mecânico, a indústria se transformou no sentido do taylorismo-fordismo e da linha de montagem, com consequências pragmáticas na orientação curricular da educação.

Depois da Segunda Guerra Mundial, Taiichi Ohno desenvolveu, no Japão, um novo modelo produtivo, o toyotismo ou modelo japonês, que ganhou força nos mercados americano e europeu, a partir da crise do capital nos anos 1970. Este caracteriza-se pela flexibilização da produção (nova organização do trabalho, das matérias primas e dos produtos), automatização, trabalhadores qualificados, trabalho em equipe, controle da qualidade total, aumento da produtividade, maior competitividade entre os trabalhadores, e com reflexo nas relações de trabalho no sentido de sua desregulamentação, do desemprego, da terceirização, da precarização dos vínculos de trabalho. ${ }^{13}$

Essas transformações na produção refletiram-se na educação nos anos 1990, no sentido de adaptação do ensino médio, sua gestão, currículo e avaliação, ao mercado, a exemplo das mudanças trazidas pelo Decreto n. 2.208/1997 e, em escala ampliada, pelo Pronatec nos anos 2000, e como sinaliz, em 2015, o documento "Pátria Educadora". Em seus termos, "qualificar o ensino público no Brasil surge dentro de contexto maior: a construção de uma nova estratégia de desenvolvimento nacional". Esta deve se dar na "travessia para uma outra estratégia de desenvolvimento: produtivismo includente", para um "novo modelo de desenvolvimento produtivista, capacitador e democratizante" para alcançarmos "vantagens comparativas na economia mundial" (BRASIL, op. cit., p. 4).

A análise sobre a história do trabalho e da educação no Brasil indica que o sentido do "produtivismo includente" são as necessidades do mercado, da produção flexível (HARVEY, 1997, grifo do autor). Quanto às alegadas "vantagens comparativas" na educação da população, duas notícias paralelas na imprensa sinalizam quão pouco realista é esta afirmação - salvo se seu sentido for de continuidade e/ou aumento dos empregos de baixa qualificação e baixos salários, ou de terceirização e de trabalho precarizado.

O primeiro artigo, trata de pesquisa realizada pela Unesco em 2013 , sobre níveis de aprendizagem em matemática e leitura, com 134 mil estudantes do 4ㅇ. e do 7ㅇ. ano, de escolas privadas e públicas de 15 países latino-americanos. A maioria dos estudantes brasileiros ficou nos níveis mais baixos da avaliação (I e II), em uma escala de níveis I a IV (MARIZ, 2015). Em outra página, no mesmo dia, uma matéria contrapõe-se à primeira notícia, mostrando o corte de gastos de 8,6 bilhões, sendo 57,2\% nos investimentos nas áreas sociais, PAC (Programa de Aceleração do Crescimento), Saúde e Educação (DOCA; BECK, 2015). Retomando a análise de Azevedo (op. cit.), vemos que "Comparar quem investe, em média, dois mil dólares aluno / ano com países que investem de oito a doze mil dólares aluno / ano, além de tecnicamente equivocado, é moralmente injusto" (p. 5).

Outras questões postas pelo documento em termos "normativos" tem sido objeto de pesquisa e discussão no país. Dentro dos objetivos deste texto, limitamo-nos à reflexão crítica sobre a EPT. Temos uma visão da realidade fortemente marcada pelos impactos científicos e tecnológicos no cotidiano de todos nós e uma visão social de qualidade do Ensino Médio e da EPT. Propomos a educação básica como formação humana que, ao contrário da fragmentação funcional

${ }^{13}$ Sobre o modelo japonês, entre outros, v. Bonazzi; La Rosa, 1993. 
ao mercado, se realize como formação integrada entre conhecimentos gerais e profissionais, tendo o trabalho como princípio educativo (GRAMSCI, 1981), o que significa uma outra qualidade da educação.

Pelo trabalho, o ser humano produz os meios de vida e reproduz a si mesmo, produz conhecimento, relaciona-se com os demais e se educa. A educação profissional é o locus mais visível da educação pelo trabalho, seja no sentido técnico e tecnológico, seja no sentido político, como movimento que oscila nas duas direções: quer como educação pelo trabalho na sua negatividade, enquanto submissão e expropriação do trabalho, como na sua positividade, enquanto espaço de conhecimento, de luta e de transformação das mesmas condições.

O que se observa é que, à medida que a escola adquire a finalidade de preparar para as exigências da produção capitalista, ela assume, também, as exigências da ordem social desenvolvida nos processos de trabalho, tais como disciplina, exatidão, cumprimento estrito dos deveres, pontualidade, contenção corporal e afetiva, submissão física, técnica e moral. Os objetivos não têm sido a formação humana, mas o aumento da produtividade da mão de obra, a redução dos custos da produção e o aumento a lucratividade dos negócios.

A educação profissional tem sido utilizada como uma estratégia de hegemonia política na educação, persuadindo os próprios trabalhadores e seus filhos de que esta formação para o trabalho é melhor do que a rua. E aqueles que não tiveram a escola regular no tempo previsto, convencem-se de que seria melhor uma educação profissional abreviada, funcional a uma atividade laboral, para lhes dar condições de inserção/reinserção no mercado de trabalho. Reforçase no país o consenso sobre as vantagens de uma formação profissional que, comparada ao ensino médio, aos conhecimentos gerais, de nada serviria aos trabalhadores, porque aqueles não teriam uma aplicação imediata. Estabelece-se a crença de que, dentro de suas condições materiais da vida que levam, não há outra alternativa.

A relação trabalho e educação se enraíza nas condições de vida, educação e trabalho na sociedade em que vivemos, no caso, o Brasil, uma sociedade de classes elitista, moralmente conservadora de suas benesses. Com base na divisão social do trabalho e na apropriação privada dos produtos do trabalho coletivo, expresso na riqueza social concentrada em bens e serviços (educação, cultura, ciência, tecnologia, arte, comunicação etc.) busca-se legitimar a distribuição extremamente desigual dos benefícios da riqueza entre as classes sociais.

A produção do conhecimento em educação profissional e tecnológica implica a compreensão histórica de como as políticas conduzem a esses resultados. Implica também o conhecimento de como são representadas ao nível dos discursos e das leis produzidos pelos sujeitos envolvidos nos acontecimentos e que têm acesso ao poder de decisão.

Tratando-se do campo trabalho e educação, os diversos aspectos tangenciados pela análise crítica, sobre a forma voluntariosa e pragmática das reformas educacionais no Brasil, não nos exime do exercício de completar esta análise a partir do materialismo histórico, como buscaremos fazer nesta terceira parte do texto. 


\section{A PRODUÇÃO DO CONHECIMENTO NAS CIÊNCIAS HUMANAS E SOCIAIS E A EDUCAÇÃO}

Em termos de uma concepção histórica e dialética da EPT, o termo configuração expressa apenas uma parte da questão tratada neste texto, a funcionalidade da educação profissional ao mercado de trabalho. Assumimos que a realidade econômica, política e social, incluindo a cultura e a educação, não é um aglomerado de partes, mas de relações sociais. Concebê-la em termos históricos e dialéticos, significa situá-la na totalidade social à qual pertence. Implica buscar uma articulação integrada das mediações que a constituem no todo que lhes dá significado, assim como situar historicamente os fenômenos, no espaço-tempo em que ocorrem, a partir da intervenção dos sujeitos sociais envolvidos, como parte do mundo econômico e social.

Neste sentido, o termo configuração não é alheio à EPT, mas reduz a capacidade humana à submissão produtiva. Do ponto de vista dialético, a pesquisa e as práticas educativas a incluem na totalidade social onde pode ganhar sentido educacional e significado social, como mediação de um projeto político-educacional. Busca-se, assim, resgatá-la como parte da formação humana, da educação omnilateral e do trabalho como princípio educativo.

Neste contexto teórico, duas orientações conceituais presidem e se complementam na pesquisa nas ciências humanas e sociais. A primeira é concepção da história como produção social da existência (MARX; ENGELS, 1979); a segunda é o método da crítica à economia política para a análise do sistema capital e a contradição capital e trabalho (MARX, 1980), sintetizados por Jaime Labastida (1983), como a história como processo e a história como método. Para reconstruir a historicidade de um fenômeno ou objeto, de modo especial, utilizamos os conceitos de totalidade social, mediação, contradição, particularidade, que são fundamentais para as pesquisas no campo do trabalho-educação. ${ }^{14}$

Diferente da historia tradicional que registrou a vida humana dando protagonismo aos heróis, aos poderosos, aos grandes feitos, Marx elevou todos os atos da vida humana ao nível do acontecimento. A história é a produção social da existência (MARX, 1979). Esta é sua concepção de história, tão bem apropriada por alguns historiadores que incorporaram novos temas, novos objetos, os grandes acontecimentos e os fatos do cotidiano, todavia, sem reconhecer a nova qualidade do ofício do historiador. É o caso de Peter Burke (1991) que faz um detalhado estudo da École des Annales ou História Nova e assinala algumas de suas características de renovação e de aproximação da história com as ciências sociais:

Em primeiro lugar, a substituição de uma história narrativa de acontecimentos por uma história problema. Em segundo lugar, uma história de todas as atividades humanas e não apenas história política. Em terceiro lugar, visando completar os outros dois objetivos, a colaboração com outras disciplinas, tais como a geografia, a sociologia, a psicologia, a economia, a linguística, a antropologia social e tantas outras (p. 12-3).

Entretanto, entre as diversas correntes historiográficas permanecem as controvérsias sobre o que são os relatos, as narrativas, os discursos que se elaboram sobre a vida em sociedade. Os fenômenos, nas suas diferentes formas de se fazerem presentes, estão sujeitos a explicações diferenciadas entre os pesquisadores, dependendo de sua visão de realidade, de como concebem

${ }^{14}$ Para detalhamento destes conceitos, ver Ciavatta, 2001. 
a produção do conhecimento e de que metodologia se servem na realização da pesquisa. As diferenças também se fazem sentir no reconhecimento e análise, ou não, da contradição capital e trabalho, das classes sociais e das lutas de classe.

Na reconstrução histórica, do ponto de vista do materialismo histórico, este processo se dá através de um movimento permanente entre a memória dos acontecimentos, a observação de sua transformação e dos novos fenômenos que tomam forma na realidade social. Para o historiador Jorn Rusen (2009), "A memória torna o passado significativo, o mantém vivo e o torna uma parte essencial da orientação cultural da vida presente". A história é uma forma elaborada de memória que vai além dos limites da vida individual. O passado é rememorado em uma unidade de tempo que se abre para o futuro e permite aos sujeitos sociais uma interpretação das mudanças "para ajustar os movimentos temporais de suas próprias vidas" (p. 164).

Nos termos do materialismo histórico, buscamos fazer a reconstrução histórica ao nível do pensamento, sem abrir mão da relação entre o concreto, o objeto que é ponto de partida de toda reflexão, e o concreto pensado, com todas as suas determinações, a exemplo da análise da população (MARX, 1977, p. 228). Assim, as categorias ou conceitos utilizados não são abstrações e não podem ser tratados apenas como termos, como discursos. Eles são capazes de traduzir, aproximadamente, o objeto de estudo tendo por base a realidade exterior com sua forma e materialidade.

De forma complementar, mas não menos importantes, indicamos alguns pressupostos metodológicos da pesquisa histórica, segundo o historiador Traverso (2012): ( i ) contextualização: significa tratar os objetos de estudo na conjunto das relações sociais que o constituem; ( ii ) historicização: situá-los no espaço-tempo dos acontecimentos em que ocorrem; ( iii) comparação: distingui-los na sua especificidade ; ( iv ) conceituação: trata-los teoricamente, não apenas para identificá-los ou descrevê-los, mas para buscar seus determinantes, suas "múltiplas determinações" (p. 17).

São as relações, tensões, conflitos entre as mudanças conjunturais e a materialidade estrutural de uma determinada sociedade, o tecido social que nos permite apreender, de forma dialética, o sentido e a natureza das alterações de um determinado momento histórico. A produção da existência em sociedades profundamente desiguais como a brasileira, em um país com alto nível de superexploração do trabalho (MARINI, 2000), país tragicamente caricaturado na imagem do "ornitorrinco" (OLIVEIRA, 2003), ocorre em um campo onde se situa o que, hoje, soe ser denominado a configuração da EPT, sinalizando que toda a educação (níveis fundamental, médio e superior) deve estar a serviço do mercado.

\section{CONSIDERAÇÕES FINAIS}

A reflexão sobre as políticas educacionais expressas nas três orientações apresentadas, as reformas empresariais, seja como leis, seja como documento de posição e sua implementação pelo Estado, evidencia e reitera o modelo privatista, produtivista e conservador da sociedade de classes desigual que somos. Historicamente, traçou-se a configuração do Ensino Médio e da Educação Profissional e Tecnológica para a manutenção do modelo empresarial a serviço da lucratividade para o mercado. 
No entanto, a história registra também, as lutas contra hegemônicas à visão simplificadora de tratar a educação como uma configuração, um conjunto de pontos e linhas ou um expediente de "formatação". Vista como fenômeno histórico, parte da totalidade social constituída pelo conjunto das relações estabelecidas ao longo da vida, nos seus diversos níveis e estágios, o trabalho e a educação podem ser mediações humanizadoras da vida individual e coletiva.

Assumimos, assim, uma visão dialética da realidade sempre em processo de movimento e de transformação. Nas escolas públicas, mesmo submetidas a precárias condições de estrutura e de condições de trabalho do corpo docente, nossos jovens estudantes não são autômatos teleguiados, nem revolucionários espontâneos. Também os professores, os gestores e suas instituições não são todos seres passivos, diante das várias pressões vindas da (des)ordem social e de suas políticas interessadas e conformistas.

As políticas educacionais emanadas do poder do Estado e os projetos institucionais ou político-pedagógicos são traduzidos em termos teóricos, práticos, técnicos e tecnológicos por esses diferentes sujeitos que frequentam e/ou atuam nos institutos federais, nas escolas técnicas, nas escolas de trabalhadores. Há circunstâncias, tempos e espaços, diferentes conjunturas que balizam a vida social. Temos por hipótese que as duas interpretações da EPT, configuração e totalidade social, convivem, na prática, de forma matizada em uma ou outra direção. Na análise político-teórica é preciso ter claras as diferenças e as consequências sociais de cada uma delas.

\section{REFERÊNCIAS BIBLIOGRÁFICAS}

1. AZEVEDO, José Clóvis de. Pátria Educadora: uma reflexão preliminar sobre texto em discussão. Disponível em: https://avaliacaoeducacional.files.wordpress.com/2015/05/jose-clovis_pc3a 1tria-educadora-uma-reflexc3a3o-preliminar.pdf Acesso em 12-06-2015.

2. BONAZZI, Giuseppe; LA ROSA, Michele. Modelo giapponese e produzione snella: la prospettiva europea. Milano: FrancoAngelli, 1993.

3. BOURDIEU, Pierre; WACQUANT, Loic A nova bíblia do Tio Sam. Jornal Le Monde diplomatique, edição brasileira, ano 1, número 4., agosto de 2000.

4. BRASIL. Presidência da República. SAE. Pátria Educadora: A qualificação do ensino básico como obra de reconstrução nacional. Brasília: 22 de abril de 2015 . Disponível: http://www.anped.org.br/forum/uploads/Uploader/52/fc205e950677cf6ca43a4ec94085da. pdf Acesso em 21-09-2015.

5. BURKE, Peter. A Escola dos Annales. 1920-1989. A revolução francesa da historiografia. São Paulo: Unesp, 1991.

6. CASTRO, Maria Helena Guimarães de Castro. Sistemas de Avaliação da Educação no Brasil. Avanços e novos desafios. Perspectiva, São Paulo, v. 23, n. 1, p. 5-18, jan./jun. 2009.

7. CIAVATTA, Maria. O conhecimento histórico e a questão teórico-metodológica das mediações. In: ___ FRIGOTTO, Gaudêncio. Teoria e educação no labirinto do capital. São Paulo: Vozes, 2001.

8. DILMA anuncia meta de 12 milhões de vagas para a nova fase do Pronatec. Folha de São Paulo, Cotidiano, quinta-feira, 19-06-2014, p. C3 Disponível em: http://avaliacaoeducacional.com/2015/04/23/patria-educadora-i/ Acesso em 12-06-2015.

9. DOCA, Geralda; BECK, Martha. PAC, Saúde e Educação são os gastos mais afetados por corte de gasto. O Globo, Economia, sexta-feira, 31-07-2015, p. 20.

10. ELIAS, Norbert. A sociedade dos indivíduos. Rio de Janeiro: Jorge Zahar, 1994. 
11. FERNANDES, Florestan. Capitalismo dependente e classes sociais na América Latina. Rio de Janeiro: Zahar, 1975.

12. FERREIRA, Paula; MARIZ, Renata. Freio no Pronatec. O Globo, Sociedade, 11-06-2015, p. 31.

13. FONTANA, Josep. A história dos homens. Bauru: EDUSC, 2004.

14. FREITAS, Luiz Carlos de. Luiz Carlos de Freitas analisa o documento da Secretaria de Assuntos Estratégicos da Presidência da República "Pátria Educadora".

15. FRIGOTTO, Gaudêncio; CIAVATTA, Maria (orgs.). Os embates da Reforma do Ensino Técnico: resistência, adesão e conhecimento. In: A formação do cidadão produtivo. A cultura de mercado no ensino médio técnico. Brasília: Inep, 2006, p. 343-372.

16. GENTILI, Pablo; SILVA, Tomaz Tadeu (orgs.). Neoliberalismo, qualidade total e educação. 5a. ed. Petropolis: Vozes, 1994.

17. GIMARÃES. Cátia. Rumos da Educação Profissional.Versão final do Pronatec mantém as principais tendências do projeto original. Poli. Saúde, Educação, Trabalho, ano IV, n. 21p. 1618, jan./fev. 2013.

18. GOVERNO Dilma adia novamente início das aulas do Pronatec. Folha de São Paulo, Cotidiano, terça-feira, 14-04-2015, C4.

19. GRAMSCl, Antonio. Concepção dialética da história. Rio de Janeiro: Civilização Brasileira, 1981.

20. HARVEY, David. Condição pós-moderna. Uma pesquisa sobre as origens da mudança cultiral. 5a. ed. São Paulo: Loyola, 1992.

21. HEINNICH, Nathalie. A sociologia de Norbert Elias. Bauru: EDUSC, 2001.

22. LABASTIDA, Jaime. O objeto da história. Nova escrita, Ensaio, São Paulo, 5 (11/12): 161-175, 1983.

23. LEHER, Roberto. Entrevista. InformAndes, Informativo, Brasília, n. 24, p. 12-13, abril de 2013.

24. LIMA, Marcelo. A educação profissional no governo Dilma: PRONATEC, PNE e DCNEMs. RBPAE, Revista Brasileira de Política e Administração da Educação, UFG, v. 28, n. 2, p. 495-513, maio/ago. 2012.

25. MARINI, R. M. Dialética da dependência. Petrópolis; Buenos Aires: Editora Vozes; CLACSO, 2000.

26. MARIZ, Renata. Brasil se sai mal em exame da Unesco. O Globo, Sociedade, sexta-feira, 31-072015, p. 25.

27. MARX, Karl. Contribuição à crítica da economia política. Lisboa: Paulo: Estampa, 1977.

28. MARX, Karl.. O capital. (Crítica da Economia Política). 2 vol.. Rio de Janeiro: Civilização Brasileira, 1980.

29. MARX, Karl; ENGELS, Friedrich A ideologia alemã (Feuerbach). 2å. ed. São Paulo: Ciências Humanas, 1979.

30. NEY, Antonio F. V. A reforma do ensino médio técnico: concepções, políticas e legislações. In: FRIGOTTO, Gaudêncio; CIAVATTA, Maria (orgs.). A formação do cidadão produtivo. A cultura de mercado no ensino médio técnico. Brasília: Inep, 2006, p. 259-282.

31. NOVO Dicionário Aurélio. Dicionário Eletrônico. Versão 5.0. São Paulo: Positivo, 2004.

32. OLIVEIRA, Eliane. Federações tentarão barrar corte no Sistema S proposto pelo governo. $O$ Globo, Economia, quinta-feira, 17-09-2015, p. 23.

33. OLIVEIRA, Francisco de . Crítica à razão dualista/O ornitorrinco. São Paulo, Boitempo, 2003.

34. PASSOS, Roberta C. de A. O movimento Todos Pela Educação e suas ações para educação brasileira na atualidade. Grupo THESE, Seminário de Produção Científica, Uff-Uerj-EPSJV, 8 a 10 de dezembro de 2014 (digital e impresso). PRONATEC. Disponível em: http://www.vermelho.org.br/noticia.php?id_noticia=152998\&id_secao=1 Acesso em 06-062011. 
35. PROST, Antoine. "Comment l'histoire fait-elle l'historien ?" Vingtième Siècle. Revue d'histoire, v. 65, n. 65, p. 3-12, 2000. Disponível em: http://www.persee.fr/web/revues/home/ prescript/article/xxs_0294-1759_2000_num_65_1_2868 Acesso em 20-09-2015.

36. RUSEN, Jorn. (2009). Com dar sentido ao passado: questões relevantes de meta-história. História da historiografia, (2), março, 163-209.

37. SADER, Emir e Gentili. Pós-neoliberalismo, políticas sociais e o Estado democrático. São Paulo: Paz e Terra, 1995.

38. SAÍDA de Mangabeira Unger abre caminho para cortes de ministérios. Folha de São Paulo, Poder, terça-feira, 15-09-2015, p. A7.

39. TOKARNIA, Mariana. Instituições privadas farão parte do Pronatec e do Fies Técnico. Agência Brasil, Brasília, 26/03/2013, p. 1. Disponível em http://memoria.ebc.com.br/agenciabrasil/no ticia/2013-03-26/instituicoes-privadas-farao-parte-do-pronatec-e-do-fies-tecnico Acesso em 21-09-2015.

40. TRAVERSO, Enzo. I/ secolo armato. Interpretare le violenze del Novecento. Milano: Feltrinelli, 2012. 